\title{
Primary open angle glaucomas in the rhesus monkey
}

William W Dawson, Dennis E Brooks, George $M$ Hope, Donald A Samuelson, Mark B Sherwood, Harry M Engel, Matthew J Kessler

\begin{abstract}
Rhesus monkeys from the closed Cayo Santiago colony of the University of Puerto Rico demonstrate elevated ( $\geq 22 \mathrm{~mm} \mathrm{Hg}$ ) intraocular pressure in a pattern which significantly favours certain maternal lineage groupings. The colony had remained genetically pure since 1938. Of nine matriarchal lineages (matrilines) examined, two had an incidence of ocular hypertension of more than $40 \%$ and six of more than $10 \%$. Information on 18 matrilines is currently located in the colony data base which identifies each individual and its vital statistics. In 1990, six animals were moved to the laboratory in Florida. Among those from a low incidence matriline, we found abnormal optic nerve cups, pallor, reduced function of (mainly peripheral) fields, progression and loss of optic nerve axons in the presence of ocular hypertension. In another individual where the cup/disc ratio for the right eye was 0.7 and left eye 0.4 and outflow facility was normal, we excluded all other causes of optic nerve atrophy, and low tension glaucoma was diagnosed. This female was from a matriline with a low incidence of ocular hypertension. Relatively rapid aging (3-4 years/human year) monkeys with ocular hypertension and familial clustering produce a near ideal glaucoma research model.
\end{abstract}

(Brf Ophthalmol 1993; 77: 302-310)

Ophthalmology, College of Medicine, University of Florida, Gainesville, FL 32610, USA W W Dawson

G M Hope

M B Sherwood

Department of Small and Large Animal Clinical Sciences, College of Veterinary Medicine, University of Florida, USA

D E Brooks

D A Samuelson

Department of

Ophthalmology,

Montefiore Medical

Center, New York, NY, USA

HM Engel

Caribbean Primate Research Center, Medical Sciences Campus, University of Puerto Rico, Sabana

Seca, Puerto Rico

M J Kessler

Correspondence to:

Dr W W Dawson, Department

of Ophthalmology, University

of Florida, College of

Medicine, Box J-284, J Hillis
Medide of

Miller Health Center,

Gainsville, FL 32610-0284,

USA.

Accepted for publication

12 January 1993

Since 1984, with the cooperation of the University of Puerto Rico, we have had a number of opportunities to examine members of the Cayo Santiago rhesus monkey colony for diseases of the posterior segment of the eye. Cayo Santiago is a small island off the east coast of Puerto Rico. The Cayo Santiago monkey colony is unique. It was established from African and Indian monkeys in 1938 and genetic purity has not been disturbed since that time. On this island the progeny of the original colony are maintained with all animals individually identified and a daily census recorded. The social history and matriarchal lineages (matrilines) for 8-12 generations are known for each animal. The history of the colony is described by Rawlins and Kessler.'

Our earlier publications s-5 $^{-5}$ have established the high incidence of age-related macular drusen and disciform lesions in some matrilines and relatively low incidence in others. The findings on age-related macular drusen and associated changes have been summarised recently by Hope et al. ${ }^{6}$

In addition to macular disease, we have discovered high tension and low tension primary open angle glaucoma (POAG) in matrilines other than those showing high incidence of macular disease. Some of the optic nerve pathology from an individual with high tension POAG was presented at ARVO in 1991. ${ }^{7}$ Here we describe two representative matrilines, the electrophysiological details of some loss in retinal function, characteristic optic disc changes, and optic nerve histopathology. These findings establish the Cayo Santiago macaques as the only non-human primates with known, naturally occurring POAG.

\section{Methods}

No monkeys have been introduced into the Cayo Santiago colony since the original importation in 1938. All monkeys have been individually identified since 1956. Daily census records are maintained. In addition to natural forage, assayed commercial diet and rainwater are provided on the island. The original social anthropological mission of the colony has been maintained and only behavioural observations are allowed. However, during the annual medical round-up, examination, tattooing, and treatment some limited, non-invasive biological research is possible. When overpopulation becomes a problem, monkeys are removed from the colony to the parent facility on the Puerto Rican mainland at Sabana Seca. Here, the excess Cayo animals are accessible and maintained adjacent to other species and random source macaques. The Caribbean Primate Research Center (CPRC) maintains more than 2000 animals, the majority

\section{SAMPLING/SCREENING}

We have conducted 315 eye examinations on 246 monkeys of Cayo derivation. Sixty one of the examinations were repeated after 1-3 years and eight were accidental duplicates (after 1 or 2 days). Intraocular pressure (IOP) was measured on one or more days in 163 monkeys (326 eyes). Examinations were conducted both on Cayo Santiago and at Sabana Seca. Only data from animals of Cayo Santiago origin are included in the data base. No matriline information was available at times of examination therefore eliminating any measurement/pedigree bias.

Animal sedation and management methods are similar to those used in several studies of induced monkey ocular hypertension and have minimal effects on blood pressure or IOP..$^{8-10}$ All procedures were approved by the Institutional Animal Care and Use Committee and observed the NIH guidelines. Monkeys were sedated briefly (about 40 minutes) by intramuscular injections of ketamine hydrochloride $(12 \mathrm{mg} / \mathrm{kg}$, Vetalar). Pupils were dilated with phenylephrine $(10 \%$, Neo-Synephrine) and tropicamide $(1 \%$, Mydriacil). Corneas were maintained with 
artificial tears and anaesthetised with proparacaine $(0.5 \%$, Alcaine).

During the eye examinations abnormalities of the external eye and anterior segments were noted. IOP was measured by an applanation technique using a Tono-pen (Bio-Rad, Ophthalmic Division). The Tono-pen contains a calculator chip which estimates the adequacy of the individual measure and produces a digital mean pressure measure and an estimate of variance. Measures were discarded when the variance was more than 5\%. Ophthalmoscopy was completed with both the direct and indirect ophthalmoscope. Conditions allowed the estimation of optic disc pallor and cup/disc $(C / D)$ ratio in about half the animals. In some animals macular drusen were counted ${ }^{6}$ and gross refractive errors were noted when detected by the direct ophthalmoscopy. In some animals with normal anterior segment, fundus Ektachromes were made using a KOWA RC-2 fundus camera and fluorescein angiograms were occasionally done with that fundus camera's fluorescein accessories.

In 1990, six Cayo Santiago derived animals (including A25, 950, and I91) from matriline 091 were taken from the island as excess to the population limits and were examined further at the University of Florida.

\section{PATHOPHYSIOLOGY}

Losses of visual function were detected electrophysiologically in monkey I91 and monkey A25. The basis for electrical measurements has been previously described by Dawson et $a l^{11}$ for monkeys and by numerous papers which have described human electrophysiological losses in response to early fields changes from POAG. ${ }^{12} 13$ Briefly, the animals were sedated by the injection of ketamine hydrochloride ( $12 \mathrm{mg} / \mathrm{kg}$ ), anaesthetised by thiamylal (Biotal), intubated, and maintained on a mixture of $25 \%$ oxygen, $75 \%$ nitrous oxide, in the presence of a muscle relaxant (pancuronium bromide, Elkins-Sinn, $0.1 \mathrm{mg}$ / $\mathrm{kg} / \mathrm{h}$ ) and intravenous saline. Core temperature, electrocardiogram, and end tidal $\mathrm{CO}_{2}$ were monitored and held approximately constant. The fundus was visualised through a highly modified Zeiss fundus camera which was fitted with a third optical channel. Through the third channel, computer generated video grating patterns of various special frequencies ( 5 minutes of arc per phase to 300 minutes of arc per phase) were projected upon the fundus under visual control and centred upon the fovea. The stimulated fields were 15 and 30 degrees in diameter. Electrical signals produced by counterphasing of light and dark grating bars produced in this way were indicators of the functional nature of the visual fields of the retina as the retina and visual cortex responded to the stimulation. The root mean square (RMS) amplitudes were calculated off line and provided an unbiased estimate of the magnitude of the responses.

Cup/disc ratios were calculated from examination by the direct and indirect ophthalmoscopes. Photographs of the optic discs were made from normal monkeys and from rhesus 191 and 950. The Ektachrome positives were digitised and the cup rim was drawn. Digital measures of the cup and disc were used to calculate cup area and cup/ disc ratio. Possible intracranial disease was rejected after a radiography and a magnetic resonance (MRI) series with gadolinium contrast was completed. I91's axial intraocular length was measured by ultrasonography and corneal curvature by keratoscopy.

Total outflow facility (C) was measured as described by Wickham et al. ${ }^{14}$ Following measurement of basal IOP (Tono-pen), the anterior segment was tapped by a single cannula. Balanced salt solution was injected to maintain constant pressure 3 and $10 \mathrm{~mm} \mathrm{Hg}$ above the basal level for 4 minutes. Total facility was calculated from the amount of fluid infused per minute at these pressures. The result $(C=0 \cdot 18$ left and $\mathrm{C}=0.29$ right) is similar to the mean value $(C=0.214 \mu \mathrm{l} / \mathrm{min} / \mathrm{mm} \mathrm{Hg})$ for 21 rhesus eyes reported by Wickham et al. ${ }^{14}$

\section{HISTOPATHOLOGY}

Eyes from monkey 950 were enucleated within minutes after cardiac failure. Immediately, a $4 \mathrm{~mm}$ opening was made at the ora serrata and $5 \mathrm{ml}$ of chilled $2 \%$ cacodylate-buffered glutaraldehyde solution was injected into the vitreous chamber. After a few minutes the anterior segment was removed. The anterior segment, the posterior segment, and optic nerve were stored together in a $2 \%$ cacodylate-buffered glutaraldehyde solution at $4^{\circ} \mathrm{C}$ for 1 week. Sections of the anterior chamber angle showed it to be normal. A $2 \mathrm{~mm}$ long portion of the optic nerve was removed and marked for vertical and posterior orientation. The optic nerve was post osmicated (1\%) for 1 hour at room temperature, washed, dehydrated, and embedded in a Medcast-Araldite epoxy resin. One $\mu \mathrm{m}$ thick
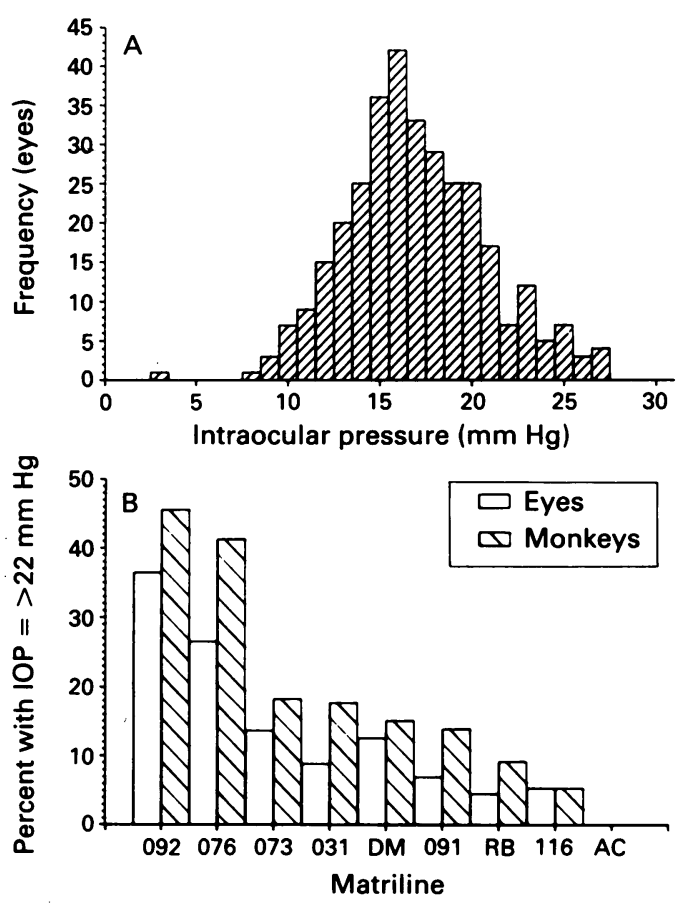

Figure 1 Demographic data on ocular hypertension in Cayo Santiago macaques. (A) Incidence of pressures in our sample of eyes. (B) Incidence of hypertension (IOP $\geq 22 \mathrm{~mm} \mathrm{Hg}$ ) in nine matrilines of the 18 matrilines available. Individual and nine matrilines of the 18 mat
analysis by eye is presented. 
sections were made and stained with toluidine blue ( $1 \%$ aqueous solution). Dorsal ventral and medial lateral planes of orientation were identified and marked on each slide.

As described in tissue from normal monkey eyes with ocular hypertension induced by Quigley and Homan, ${ }^{15}$ the slides were morphometrically evaluated ${ }^{16}$ by an IBAS image analysis system (Kontron-Zeiss, Munich, Germany).
Except for the regions of the central artery and vein and the pial septae, the entire area of the cross section of each optic nerve was measured. Each optic nerve was then subdivided into 16 segments of approximately the same area, following the procedures described by Quigley et al. ${ }^{17}$ Using oil immersion light microscopy $(\times 2000)$ eight areas were selected in each segment and photographed by Nikon Microfot.

A
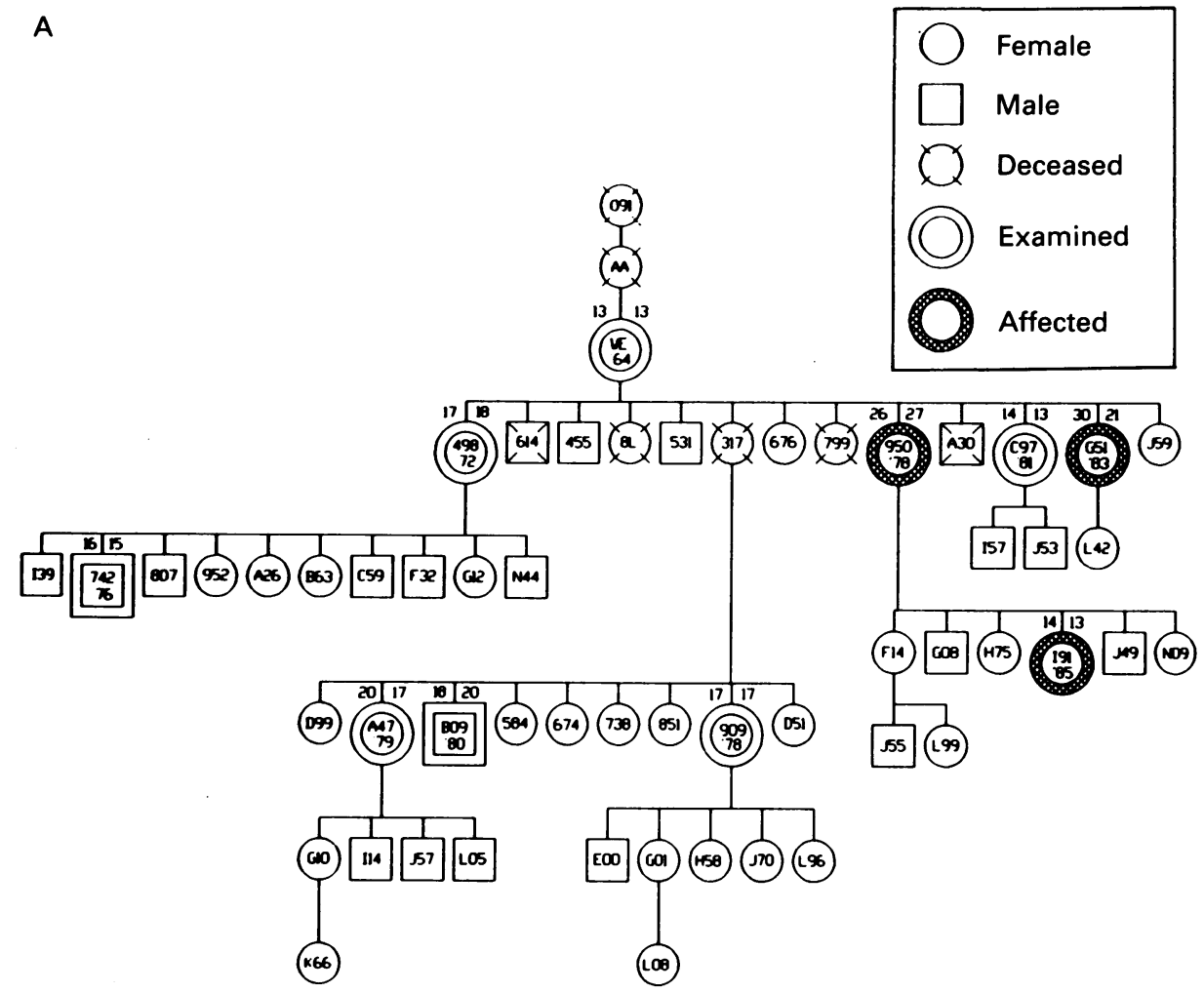

B

Figure 2 Partial matriline diagrams of monkeys related to those examined and found to have an intraocular pressure of $22 \mathrm{~mm} \mathrm{Hg}$ or more or to have a high cup/ disc ratio $(\leq 0.5)$ with pallor. Internal symbols are identification number and (below) date of birth expressed as ' $x x$. $(A)$ Matriline 091 typical of low incidence ocular hypertension. (B) Relatively higher incidence matriline (076). Pressures are indicated (left and right) above each examined animal. See text for details.

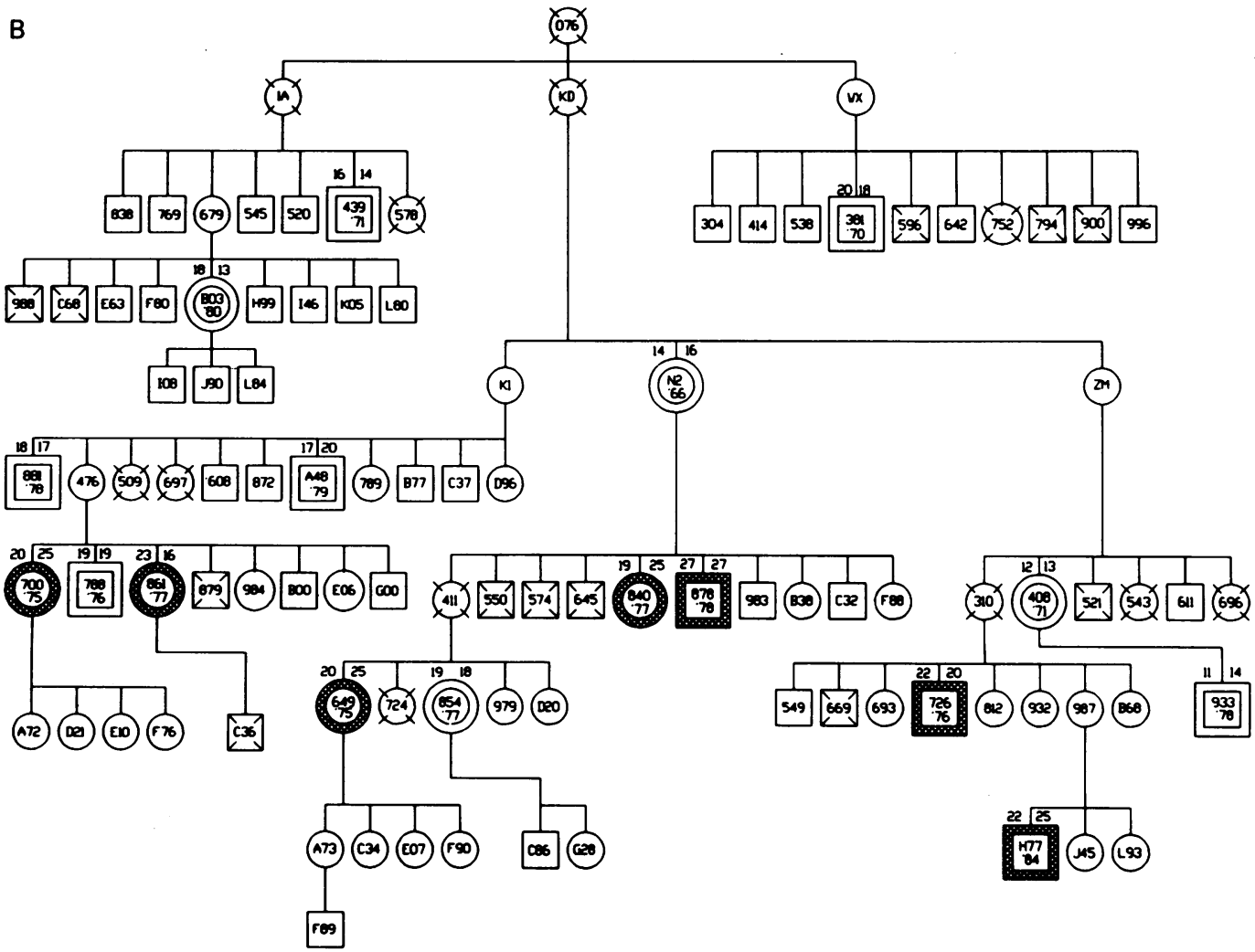


Each field was 30 by $40 \mu \mathrm{m}$ for an area of 1200 $\mu \mathrm{m}^{2}$ per field. Within each field, axons were counted by the IBAS system and their mean minimal diameters were measured. Any axon that touched the left and inferior border of the area being measured was not included. Pial components were also excluded. The diameter measures were sorted into 20 bins, ranging from $0 \cdot 2$ to $4 \cdot 0 \mu \mathrm{m}$.

\section{Results}

INTRAOCULAR PRESSURE

Intraocular pressures were measured by applanation tonometry in late morning or early afternoon. Pressures were measured one or more times on 163 monkeys ( 326 eyes). Examinations of 43 of these were repeated 1-3 years later. IOPs from individuals dilated for subsequent fundus examination were not significantly different from 49 other individuals undilated but otherwise treated identically. The IOP differential between dilated and undilated groups was 0.62 $\mathrm{mm} \mathrm{Hg}$. There was no significant difference between the groups in numbers of animals with pressures $\geq 22 \mathrm{~mm} \mathrm{Hg}$, which totalled 31 individuals. This value is widely accepted as the threshold for IOP abnormality in conscious humans. ${ }^{18} 19$

It seems unlikely that any of our results are contaminated by anaesthetic or time cycle influences. Bito $e t a l^{20}$ reported losses in IOP (17.6$11.3 \mathrm{~mm} \mathrm{Hg}$ ) in a trained rhesus after the injection of a small amount of sodium pentobarbitone. Normal or high doses of ketamine had no significant effect on this monkey or on the IOP of 35 others studied for dose rate, duration of anaesthesia, and effects on final IOP. In a sample of 102 animals, aged 7 months to 21 years, there were peaks (about $1-2 \mathrm{~mm} \mathrm{Hg}$ ) in the time of day/IOP function at 9 am and $3 \mathrm{pm}$. These were not significant.

IOP, optic disc pallor, and the $\mathrm{C} / \mathrm{D}$ were estimated in 132 monkeys. Of this number, 24 exhibited pallor and $C / D \geq 0 \cdot 4$. Six monkeys exhibited asymmetric pallor and $C / D \geq 0.5$. Some showed asymmetrical cup shapes. There was high subjective agreement between the extent of pallor and the optic cup size. Thirty eight eyes (30 individuals) had $C / D \geq 0 \cdot 4$. Twenty nine eyes (21 individuals) had IOP values $\geq 22 \mathrm{~mm} \mathrm{Hg}$. Thirty one eyes ( 24 individuals) had $C / D \geq 0.4$ where IOP $\leq 20$. Five animals showed combined C/D, IOP abnormality. C/D estimations were repeated on successive years (in the absence of previous records) and on the same visit (accidentally). Measures of C/D were made on 68 eyes/34 monkeys on successive years by any of three examiners. The mean difference between annual estimates was 0.054 (SD 0.125). For repeated measures on the same visit (12 eyes/six monkeys) the mean difference was 0.042 (SD 0.082).

The mean age of our sample of Cayo Santiago rhesus monkeys was 11.6 (SD 5.2) years. Ordy and Brizzee ${ }^{21}$ have estimated that one monkey year of life is equal to 3-3.5 human years. Therefore, our sample covered approximately 10-95 human years. The frequency distribution of IOPs in our sample of 326 eyes is shown in Figure 1A. The distribution mean IOP is 16.9 (SD 3.8 ) $\mathrm{mm} \mathrm{Hg}$. We found no significant dependence of IOP on age. Mean IOP in the eyes of males $(17 \cdot 4, \mathrm{SD} 3.9 \mathrm{~mm} \mathrm{Hg})$ were significantly higher $(\mathrm{p}<0.05)$ than in those of females $(16.45$, SD $3.65 \mathrm{~mm} \mathrm{Hg})$. However, the difference was small and tests for differences in IOP based upon individuals rather than eyes were insignificant.

At this time, there are 18 matrilines of Cayo Santiago derivation in Puerto Rico. In our sample, we found IOPs $\geq 22 \mathrm{~mm} \mathrm{Hg}$ in individuals from nine matrilines. Data from six other matrilines have not been included because sampling in them involved fewer than 10 animals. Two of the nine matrilines (Fig 1B; 092 and 076$)$ produced $44 \%$ affected animals $\left(\chi^{2}\right.$, $\mathrm{p}<0.001)$. Yet, mean IOP did not vary significantly among matrilines, nor did age or numbers of animals sampled, except for 091 which supplied a large number of individuals.

Figures $2 \mathrm{~A}$ and $\mathrm{B}$ show partial matriline diagrams (pedigrees) taken from our CPRC data base. There is a low incidence (091) and high incidence (076) matriline. Only lineages of 'examined' or affected animals are shown to conserve space. The 076 diagram covers seven generations and the 091 diagram covers eight generations. The animals which we have examined for intraocular pressure are symbolised with double boundaries and those which were affected (IOP $\geq 22 \mathrm{~mm} \mathrm{Hg}$ ) are shown with double boundaries and cross-hatching. Animals deceased are identified by ' $X$ ' and animal number. Animals not examined are identified by number of boundary only. Matriline 091 (Fig 2A) represents 280 monkeys. Of these only the 57 progeny of matriarch WE are shown since she had 36 siblings with many offspring. In the 091 sample, six of 31 examined monkeys had ocular hypertension or optic atrophy. Three of these are among the WE progeny (Fig 2A). Normotensive monkey 191 will be discussed later. Matriline 076 represents a smaller group with 188 individuals; 102 are shown in Figure 2B; 17 were examined and seven were affected.

Of the animals examined in group 091, 19\% had ocular hypertension; and $41 \%$ in group 076 had ocular hypertension. One animal (191) in matriline 091 had pronounced excavation of the optic disc in the absence of ocular hypertension. In Figure 2, IOP is indicated as two integers (left eye; right eye) immediately above the symbol. The animal number is indicated in the upper part of the interior of the symbol and date of birth in the lower portion. Date of birth is prefixed by an apostrophe.

During our visits to the island, we were able to examine the optic discs of 132 normotensive (IOP $\leq 20 \mathrm{~mm} \mathrm{Hg}$ ) animals. Of this number, 24 exhibited some pallor and $C / D \geq 0.4$ and six $\geq 0 \cdot 5$. All of the six were asymmetric for pallor/ disc shape. In human infants of this physical size ( $<3$ years) $C D \geq 0.4$ is rare in normals and common in patients with glaucoma. ${ }^{22}$

Six animals from Cayo Santiago were brought to the University of Florida for further examination. Data from three are presented. Number 950 and its offspring, number I91, are from 
matriline 091 (Fig 2B), as is female A25. A25 is a clinically normal female that was born in 1980 . Her IOPs were taken on five occasions in January of 1989 and yielded a mean IOP of $12 \cdot 2$ (SD $1 \cdot 2$; range $11-14)$ in the right eye and mean $=12 \cdot 5$ (SD $1 \cdot 3$; range $10-14$ ) in the left eye. Female 191 was born in 1985 and in January of 1992 displayed $C / D$ ratios estimated to be 0.7 in the right eye and 0.4 in the left eye. Intraocular pressures measured $(\times 15)$ in 1990 averaged $14 \mathrm{~mm} \mathrm{Hg}$ (range $10-15)$ in the right eye and $13 \mathrm{~mm} \mathrm{Hg}$ (range 6-19) in the left eye and were normal again in 1991-92 with a mean of 11.6 (SD 0.74 ; range $11-14, \mathrm{n}=12$ ) in the right eye and $12.0(\mathrm{SD} 0.92$; range $11-15 ; \mathrm{n}=$ 12 ) in the left eye. Outflow facility of I91's right $(C / D=0.7)$ and left eye $(C D=0.4)$ were within normal limits for rhesus, ${ }^{14}$ which is similar to values reported by $S$ chuman ${ }^{23}$ for human. Female rhesus 950 was born in 1978 and in January 1988 showed C/D ratios of 0.7 in the left eye and 0.5 in the right eye. At that time, IOPs were taken repeatedly to produce a mean $\mathrm{IOP}=$ $26 \cdot 1$ (SD 1.9 ; range $24-30 ; n=6$ ) in the right eye and mean $=27 \cdot 5(\mathrm{SD} 2 \cdot 3$; range $23-30 ; n=6)$ in the left eye. Subsequent measures (1991) of IOP for female 950 have yielded consistent results $>25 \mathrm{~mm} \mathrm{Hg}$, bilaterally, measured morning and afternoon.

Figure 3 shows the optic discs of the right eyes of each animal. These are reproduced digitally from transparencies. The very light areas normally associated with the optic cups are shown as the darker regions of the papilla. These are digitally outlined and marked with arrows. Note especially the poor resolution and/or absence of temporal fibre-layer striations of the papillomacular bundle in female I91. The MRI series, cranial radiographs, anterior segment and gonioscopic examination, and general neurological results on 191 were all normal. The high $191 \mathrm{C} / \mathrm{D}$ was a chance finding among animals shipped to Florida. Clinical and digital calculations of C/D values are presented in Table 1 .

Figures 4A and 4B describe the eye and visual cortical responses produced (sequentially) by $50 /$ 50 gratings of seven sizes projected upon the fundus during intervals over approximately 8 minutes. Figures $4 \mathrm{~A}$ and $4 \mathrm{~B}$ describe the responses from normotensive female I91. Data for Figure 4A were collected in 1990 and Figure 4B in early 1992. The data shown in Figure 4A are typical of normal cortical and retinal responding to counterphased gratings of several spatial frequencies. The spatial tuning function (STF) is very similar to that produced by normal female A25. Typically, there is a minimum which is approached at the smaller sizes, a subsequent peak, and a second minimum at the largest stimulus size. The 1992 STF from I91 differs mainly by reduced response amplitude, both at the visual cortical recording site and from

Table 1.Cup/disc ratios of three monkeys measured clinically and digitally (two methods) from photographs

\begin{tabular}{llll}
\hline Animal & Clinical & $\begin{array}{l}\text { Digital } \\
\text { area }\end{array}$ & $\begin{array}{l}\text { Digital } \\
\text { width }\end{array}$ \\
\hline A25 (normal) & 0.4 & 0.21 & 0.36 \\
950 (IOP $>25 \mathrm{~mm} \mathrm{Hg}$ ) & 0.6 & 0.22 & 0.54 \\
191 (atrophy) & 0.7 & 0.57 & 0.85 \\
\hline
\end{tabular}

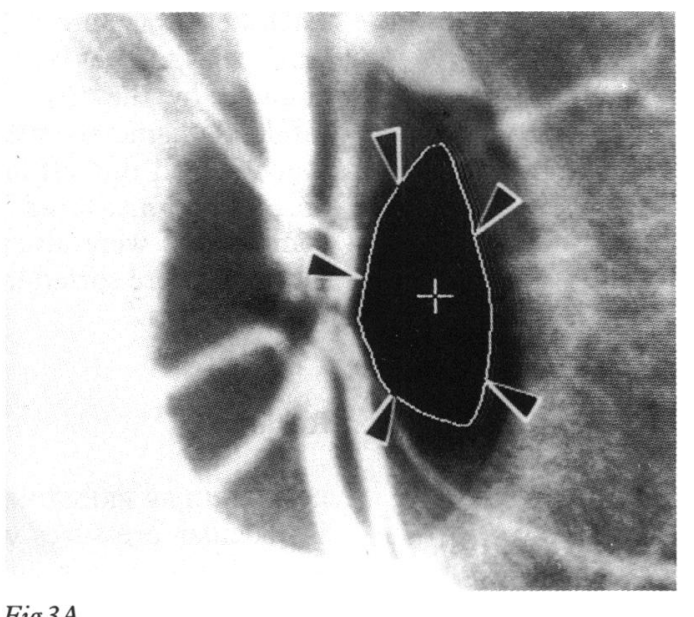

Fig $3 A$

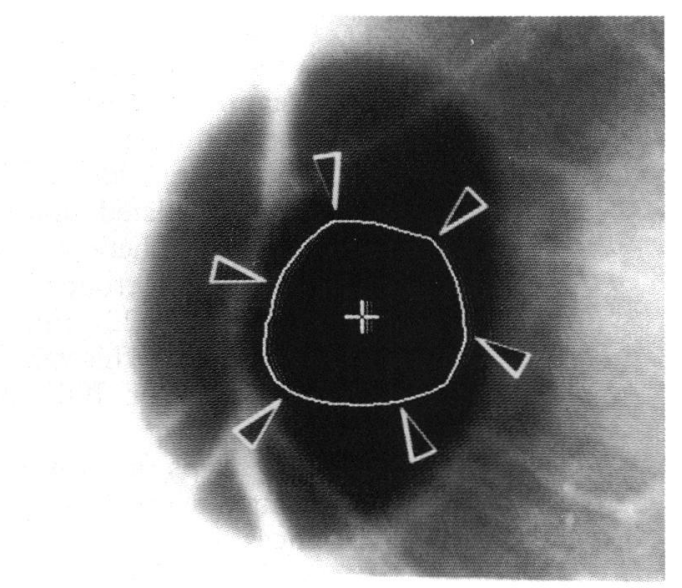

$F i b 3 B$

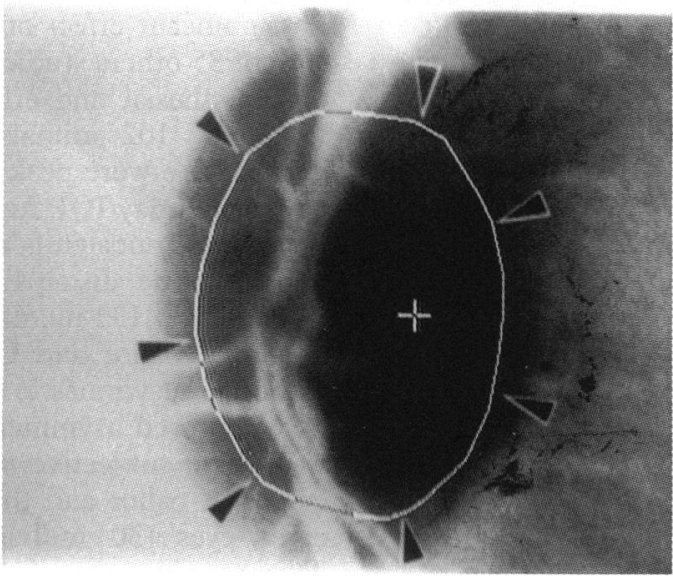

Fig $3 C$

Figure 3 Optic disc photographs have been digitised and are presented as negative prints from Kodachrome positives. Cup rims are outlined and marked by arrows. $(A)$ Normal rhesus $A 25$, right $C / D=0 \cdot 4$. (B) Abnormal disc, rhesus 950 , right $C / D=0 \cdot 6$. (C). Abnormal disc, rhesus 191 , right $C / D=0 \cdot 7$. Digital values were used to produce Table 1 .

the eye itself. The loss may be more profound at the eye electrode than at the cortical electrode.

Figure 5 summarises the STFs originating from the right retinas of $I 91$ and A25. Eye data from the earlier and later recordings from animal I91 and from the normal A25 are shown. The histograms represent the mean values of all of the STF components over the full range of grating sizes. That is, the $30^{\circ} \mathrm{STF}$ (Fig $5 \mathrm{~A}$ ) represented on the fields ordinate for animal $I 91$ is the equivalent of summing all the eye data points 
Figure 4 Spatial tuning functions produced by retinal $(O)$ and cortical $(\nabla)$ origin in response to a range of counterphased gratings (5-750 minutes of arc) projected onto the right fundus. (A) Measures from I91, right eye in mid-1990. (B) Measures from 191, right

Figure 6 Peripheral optic nerve axons of POAG female 950, left and right eye counted in regions and scaled by diameter. (A) Dorsal periphery (see inset) equal area. (B) Ventral periphery. Abscissa values are mean axons/size/unit area. Abscissa mean the ordinate (size-range). contrast evoked signals of eye in early 1992. including four divisions of numerals are provided below
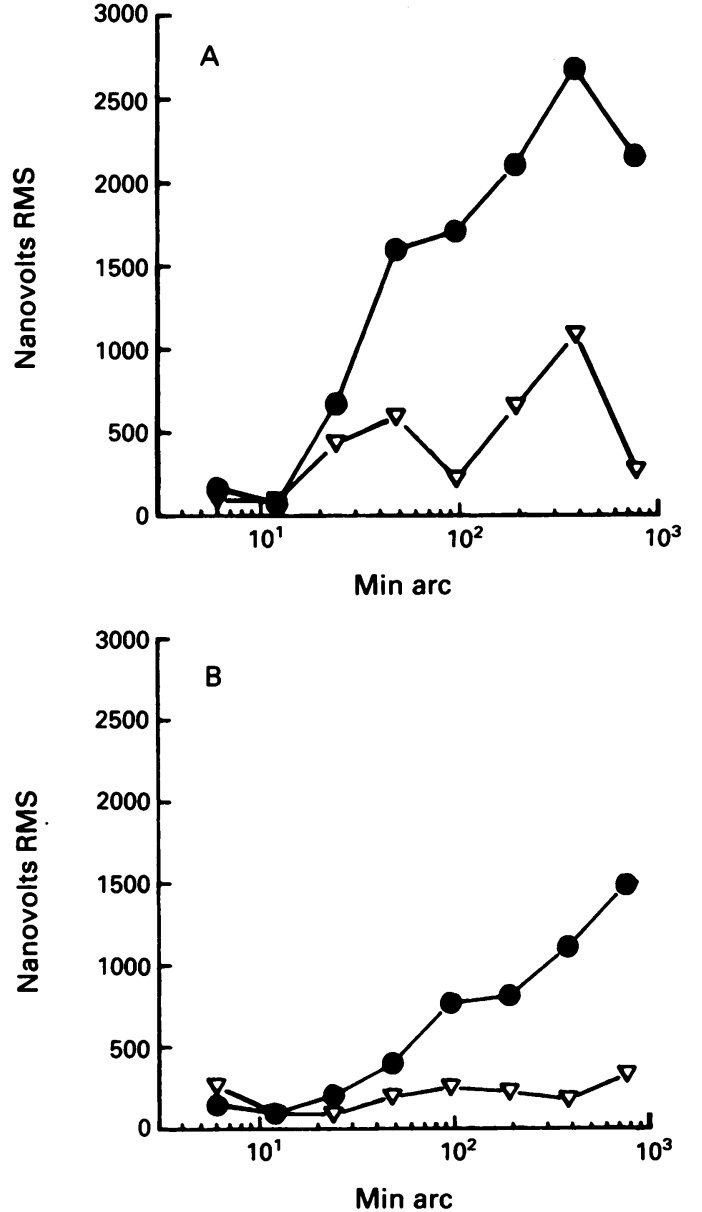

from Figure $4 \mathrm{~A}$ together and deriving a mean. In addition to the $30^{\circ}$ stimulus field sizes used in the generation of Figure 4A and B, Figure 5 also

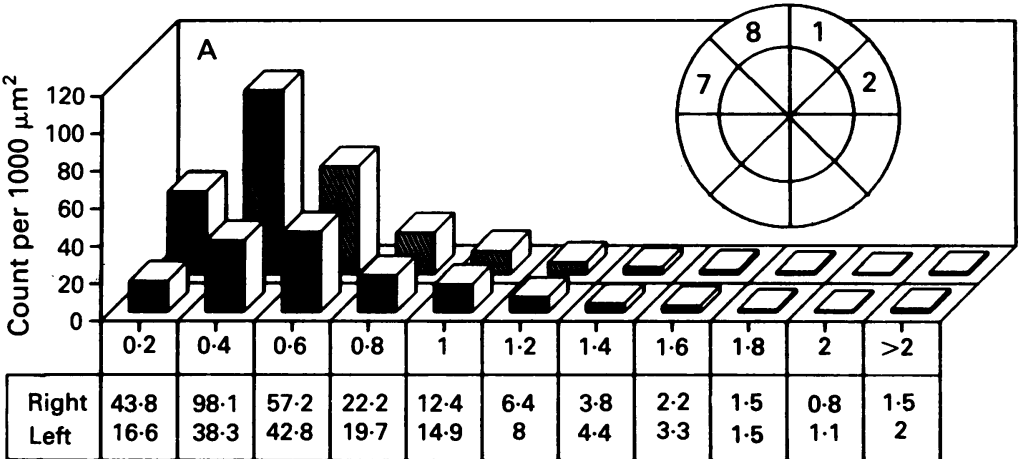

Axonal diameter

Left eye Alit Right eye

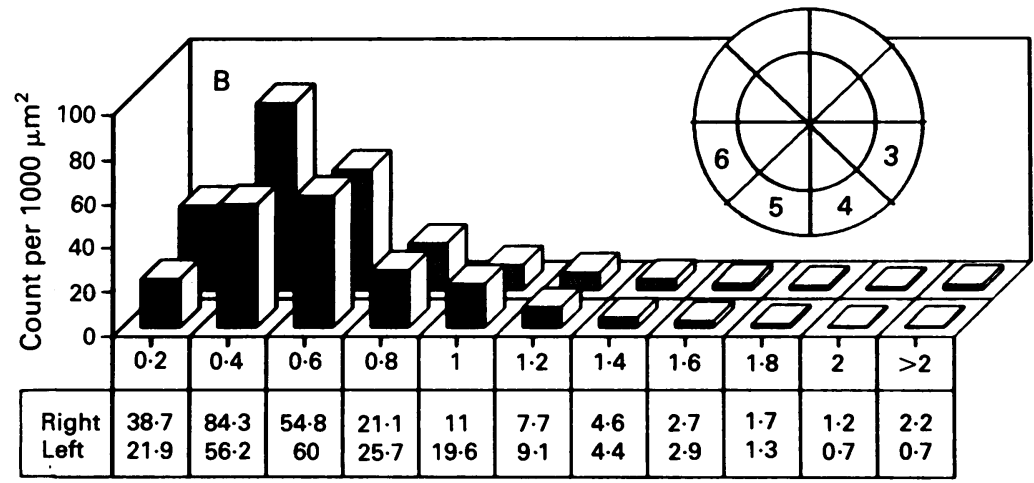

Axonal diameter
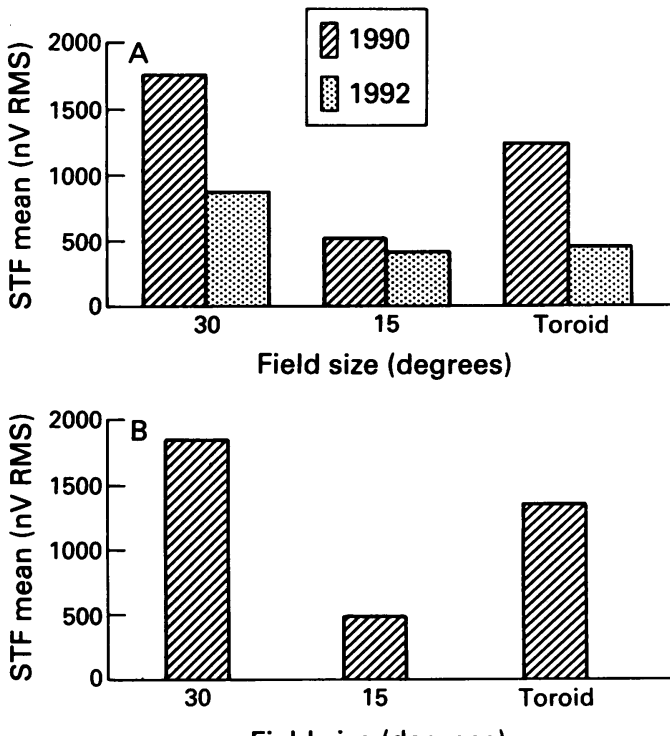

Field size (degrees)

Figure 5 Mean spatial tuning function values for the right eye of $191, C / D=0.7$ and $A 25, C / D=0.3$. STF means were calculated for a central $30^{\circ}$ diameter field, a $15^{\circ}$ diameter field and a toroidal field derived from the $30^{\circ}$ result minus the $15^{\circ}$ result. (A) Data are from $I 91$ in 1990 and 1992 . (B) Data are from normal female $A 25$.

shows the STF result from a $15^{\circ}$ field stimulus centred (as others) upon the fovea. Toroid values in Figure 5 are the result of a subtraction of the $30^{\circ}$ mean and the $15^{\circ}$ mean. Spatially, this represents the response of a toroidal field around the macula. Changes in cortical responses are not significantly different from those from the retina. Normal A25 STF means (Fig 5B) are shown for comparison.

Figures 6A and 6B show the relative left optic nerve axon loss counted by the IBAS analysis system in regions of the optic nerve of female 950 . The left eye had a $0 \cdot 7 \mathrm{C} / \mathrm{D}$ ratio and the right eye was relatively normal with $\mathrm{C} / \mathrm{D}=0 \cdot 4$. The vertical axis scale is axons measured in $1000 \mu \mathrm{m}^{2}$ samples within the measured optic nerve zones as shown in the inset. The abscissa represents axon diameter ranges into which the counts were subdivided. The range 0.2 relates to all fibres with sheath diameters of 0.2 units or less. The values below each range are means for the samples from left or right eyes. Figures 7A and 7B present similar data from the centre of this optic nerve.

Figure 8 shows a cross section of the left optic nerve $4 \mathrm{~mm}$ behind the disc and cup, from female 950. Losses from the central regions of the section are clear. Some abnormal axons remaining showed profoundly low stain uptake. Axon debris and unstained margins could be identified but did not reproduce photographically.

The left optic nerve, dorsal ventral diameter was $2.81 \mathrm{~mm}$ and horizontal was $2.3 \mathrm{~mm}$. In the total area of measurement we found 52027 axons in $0.307 \mathrm{~mm}^{2}$ of tissue. From this our Zeiss IBAS system calculated that the whole nerve $(5.08$ $\mathrm{mm}^{2}$ ) contains approximately 860000 axons. This is notably fewer than in the total of axons in the right optic nerve $(C / D=0.4$ with little pallor) where 1.22 million total axons were calculated. Potts $e t a l^{4}$ counted each fibre in sections of rhesus optic nerve and obtained totals of about 


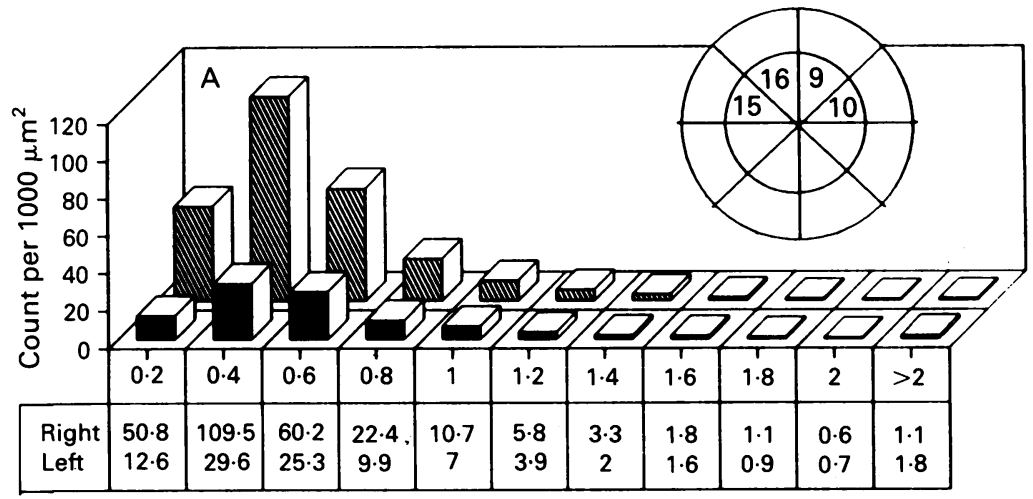

Axonal diameter

\section{Left eye $\quad \mathbb{M} W \mathbb{W}$ Right eye}

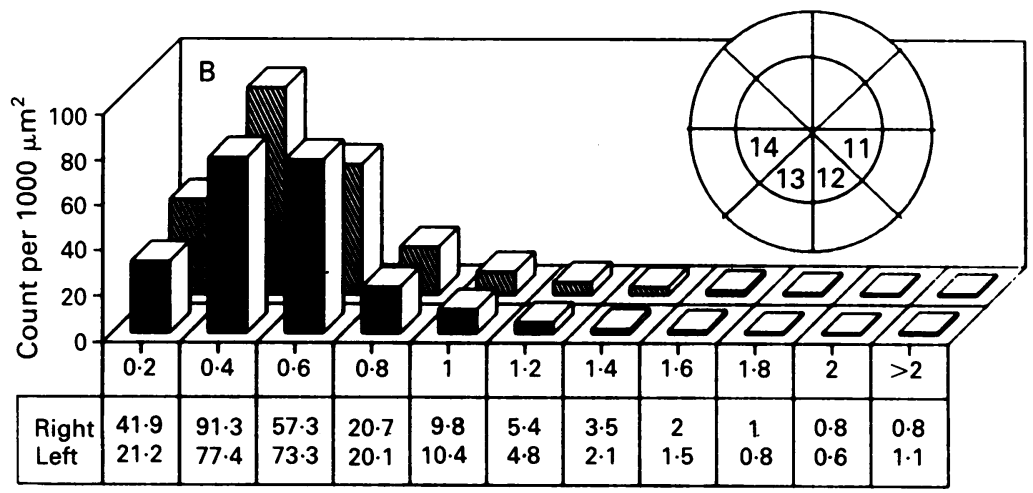

Figure 7 Central optic nerve axon size spectrum of POAG female 950.

Otherwise as Figure 6. (A) Dorsal centre. (B) Ventral centre.

Axonal diameter

1.6 million. Also using the Zeiss IBAS system, Sanche $z^{16}$ reported about 1.2 million axons in a normal, cynomolgus macaque (Macaca iris) optic nerve.

Calculations on the Sanchez et $a l^{16}$ data show that $28 \%$ of the axons are $>1 \mu \mathrm{m}$ in diameter in

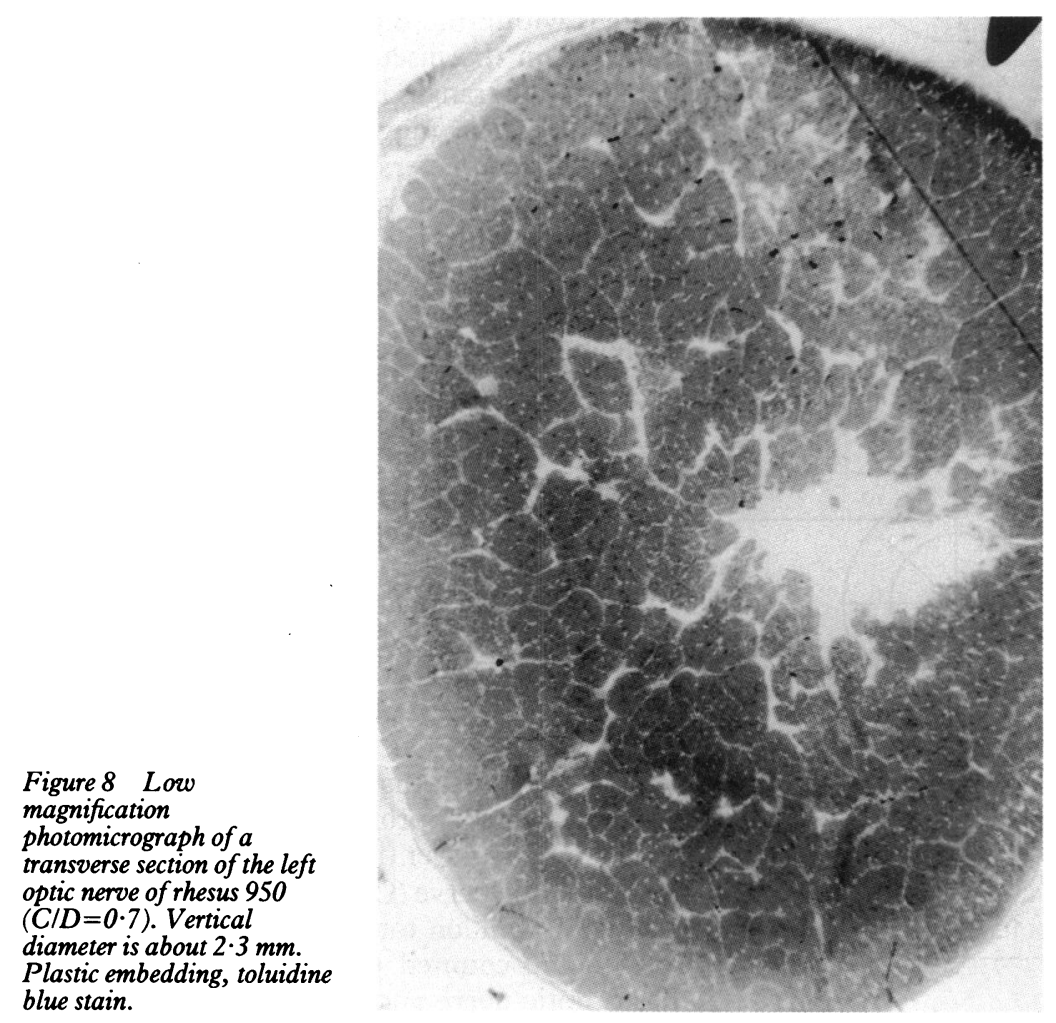

the normal eye. By comparison, our rhesus 950 optic nerve samples showed only $16 \%$ of the fibres $>1 \mu \mathrm{m}$ in diameter in naturally occurring, progressive POAG. We found moderately reduced axon densities at various sites on the left optic nerve face, except in the superior central and superior peripheral portions of the left samples where counts were reduced by $50 \%$ or more.

\section{Discussion}

The Puerto Rican monkeys' ocular pressures have been studied before. A sample of 114 animals from Cayo Santiago and La Cueva island was measured by Bito et al. ${ }^{20}$ They report a mean IOP of 14.9 (SD 2) $\mathrm{mm} \mathrm{Hg}$, which is $2 \mathrm{~mm} \mathrm{Hg}$ below those we report. Since the La Cueva colony no longer exists and several whole Cayo matrilines have been sold in recent years, it is unlikely that animals from their 1979 study are included in our sample. Nevertheless, neither set of measures are significantly different from human (for example, refs 1718 ). Bito et $a l^{20}$ reported no evidence of optic disc cupping or other glaucomatous changes in their samples of the Cayo rhesus population.

Authoritative reviews of the principles and concepts involved in classification and treatment of human glaucomas have been provided by a number of authors. Newell ${ }^{25}$ states that, 'glaucomas are a family of ocular diseases in which increased IOP may cause optic atrophy with excavation of the optic disc and characteristic loss of visual field'. This definition includes both open angle and closed angle glaucomas. In a schematic presentation of POAG classes, Newell lists low tension glaucoma (LTG) among others but provides no detail. Chandler and Grant ${ }^{26}$ describe glaucoma as a disease characterised by IOP, 'sufficient to cause either temporary or permanent impairment of vision'. They treat LTG briefly - 'in uncommon so-called lowtension glaucoma the intraocular pressure may not be abnormally high'. However, they comment that the other signs/symptoms of the disease may be the same as are found in high tension glaucoma. More recently, Werner ${ }^{27}$ traces the identification of LTG to Von Grafe in 1857 and provides a table which compares the prevalence of glaucoma with normal IOP to open angle glaucomas. Seven publications are listed, totalling 860 diagnoses. The average percent incidence of low pressure glaucoma was $43 \%$ (SD $12 \%)$. The lowest percentage reported in 45 glaucoma patients was 6.7 with the highest reported as $68 \%$ of 189 diagnoses of glaucoma. From this, we have adopted a multifactorial criterion for the identification of glaucoma in the rhesus macaque.

In the absence of macular or intracranial disease, the standard for POAG diagnosis is the progressive loss of optic nerve fibres. Also used is retinal functional loss and subsequent clinically detectable excavation of the optic disc. When data on optic nerve fibre loss are not available, we accept abnormal cup/disc ratios with the reduction of visual function as an indicator of inner retinal pathology and/or optic nerve damage. In view of the recent thinking prompted by the 
coalescence of data on the 'high' incidence of low pressure glaucoma in humans, ${ }^{27}$ the presence or absence of hypertension ( $\geq 22 \mathrm{~mm} \mathrm{Hg}$ ) is of interest to us but is not required to diagnose glaucoma in the rhesus monkey. In this respect it is interesting that normotensive monkey $\mathrm{I} 91$ is the offspring of hypertensive 950 (Fig 2A).

As in humans, large scale screening for glaucoma is most efficiently pursued by heavy dependence on applanation tonometric measurements. We managed our large scale CPRC screening of the Cayo Santiago rhesus population in this way and with ophthalmoscopy obtained a great deal of data in a short period of time (Fig 1). Electrophysiological measurements of field losses were impossible with the tropical island conditions but were done on representative animals that were shipped to Florida as a courtesy by CPRC. In the laboratory, estimation of loss of rhesus visual function by the stimulation of the retina with gratings requires slightly less time (about 8 minutes, independent of anaesthesia and preparation) than automated perimetry in humans. Data from normal female A25 in Figure 4A are typical of the resolution/ sensitivity we have seen in the past ${ }^{611}$ in the presence of good physiological optics. There is usually a STF that displays a minimum around 5 minutes of arc, a peak and reduced output at the largest grating sizes. The response magnitude of the eye signal is always greater than the cortical signal. However, the tuning and peak of the cortical signal is usually more developed. The general shape and amplitude of the right eye signals $(C / D=0 \cdot 7)$ from normotensive 191 were comparable with $\mathrm{A} 25(\mathrm{C} / \mathrm{D}=0 \cdot 3)$ when $\mathrm{I} 91$ was first tested in 1990 (Fig 4A). There was a decline of about $50 \%$ in the central $30^{\circ}$ field of the right eye signal with re-evaluation in 1992 (Fig 4B). In addition to the signal loss there was a shift of the tuning peak towards lower spatial frequencies. The left eye $(C / D=0 \cdot 4)$ changed very little.

However, the right eye's field losses $(\mathrm{C} / \mathrm{D}=$ $0.7)$ are not equal in all retinal areas. Figure 5 shows that the least progression occurred in the central 15 degrees and the greatest loss (about $60 \%$ ) in the toroidal shaped periphery. Typical early progression of human POAG is often more evident in the mid peripheral fields. Earlier (1990) test results for 191 compare favourably (Fig 5) with those from normal female A25 where $\mathrm{C} / \mathrm{D}$ is about $0 \cdot 3$. 191 cup dimensions changed minimally during the 2 year period; pallor was difficult to quantify. Function of the I91 left eye $(\mathrm{C} / \mathrm{D}=0.4)$ did not change and remained comparable with the results from normal A25 (Fig 5).

In his review, ${ }^{28}$ Schwartz considers enlargement of optic disc cupping as a common normal phenomenon often associated with aging. However, when pallor develops, visual field loss generally occurs. He considers $50 \%$ pallor as the upper extent of normality. In his drawings and figures pallor and cupping are highly correlated. He recommends patients with asymmetric pallor/cupping as 'suspect' glaucomatous patients. The pronounced pallor and cupping of the optic nerve head or its normal diameter which we see in $I 91$ is not explained by the normal axial intraocular distance measured by ultrasound or by the normal corneal curvature measured by keratoscope. Further, there was no evidence on MRI scan of an intracranial phenomenon (neoplasm or aneurism) that might contribute to I91's right optic nerve head abnormality (Fig 3). Aside from C/D, I91 appeared clinically normal.

If it is valid to apply human clinical criteria to the diagnosis of glaucoma in other primates, it seems certain that glaucoma is a significant factor in the visual health of certain Cayo Santiago macaque matrilines. We have demonstrated the pressure component, the familial cluster component mentioned by several authors, ${ }^{2930}$ the abnormal cup/disc ratio component, the normal angle, and the field loss diagnostic components typical of human POAG. In the case where the pathology data were available in female 950 , we find an overall loss of approximately $25 \%$ of the optic nerve fibres in her left eye compared with published normal numbers in related macaque strains. Further, her left eye had a significantly lower optic nerve axon count than her right eye, which had 1.2 million fibres and a normal cup/ disc ratio. It is interesting that significant loss appears in the large fibre portion of the spectrum as reported in the early histopathology of cases of human POAG by Quigley et al. ${ }^{17}$

Accurate animal models of human disease can be very useful. Yet, modelling of human spontaneous glaucoma has been limited. One useful model of POAG has been developed as an autosomal recessive trait in a strain of beagle dogs by Gelatt. ${ }^{31}$ Buphthalmic rabbits have been known for some time but have received relatively little attention..$^{32}$ The older literature on the features of experimentally induced glaucoma is reviewed by Kalvin $e t a l^{33}$ who produced ocular hypertension in owl monkeys by the injection of $\alpha$ chymotrypsin into the anterior chamber. More recently, Quigley and Hohman ${ }^{15}$ have succeeded in more controlled reduction of outflow by damaging the trabecular meshwork of cynomolgus monkeys with lasers to produce a partial functional angle closure with fluctuating elevations in IOP.

The implications of these models using induced angle closure glaucomas (IAG) for LTG or even POAG are not yet clear, although Quigley $e t a l^{17}$ have shown parallels between the monkey IAG pathology and the human optic nerve condition in POAG. ${ }^{34}$ Fischer et $a l^{35}$ have reported that there is frequent spontaneous recovery from hypertension in this model after about 1.5 years. There does not appear to be a common human parallel to this phenomenon.

In the laser induced glaucoma monkey model, large diameter optic nerve axons were found to be damaged more easily than smaller axons in both the least and best preserved areas of the nerve. ${ }^{17}$ The data indicated that fibres with a diameter from 0.35 to $0.75 \mu \mathrm{m}$ survived better in the widely fluctuating elevations of IOP found in the IAG model, than fibres with diameters from 0.85 to $1.25 \mu \mathrm{m}$. Study of 10 optic nerves from this model indicated a preferential loss (broad size range) of axons at the superior and inferior regions of the nerve head. The least damaged areas were found to be in the temporal centre, with the most severe damage localised to the nasal periphery of the superior and inferior 
poles. The optic nerve damage to CPRC monkey 950 with naturally occurring POAG was most severe in the superior nasal quadrant with a $50 \%$ or larger reduction in the fibres smaller than 0.8 $\mu \mathrm{m}$ and only slight reduction in the larger diameter fibres. The superior central regions of the nerve were similarly affected. The inferior peripheral and central areas were less affected than the superior regions, although the largest fibres in the inferior peripheral area were markedly reduced in number.

There are also reports of complex pathophysiology other than optic nerve fibre loss when IOP is elevated in (otherwise) normal eyes. ${ }^{3637}$ Although in the past local ischaemia seemed to be related to early IAG, ${ }^{38}$ a reliable relationship between vascular phenomena and low tension human glaucoma has not been clear $^{39-41}$ until recently. ${ }^{42}{ }^{43}$ As more tissue from monkeys with naturally occurring POAG becomes available, it will be interesting to see if the other monkeys àlso demonstrate widespread loss of small diameter fibres as compared to larger axons. This naturally occurring disease, with its insidious elevations of IOP, may not be identical with the laser induced primate glaucoma model.

In view of the frequency of LTG, ${ }^{27}$ an increment in the relative priority of LTG may be justified. A computer search of the world literature from 1985-90 yielded 3855 entries on the topic 'glaucoma'; of these $95(2.5 \%)$ included 'low tension', 'lower pressure', or 'normotensive' in the abstract or as a key word. The errors involved in this literature search technique notwithstanding, an underemphasis on LTG is suggested.

The finding of open angle glaucomas (both high tension and low tension) and numbers of ocular hypertensive individuals in the Cayo Santiago macaque is very encouraging for the development of new diagnostic techniques, treatments, and the genetic study of these important human eye diseases. The relatively rapid aging of the macaque makes the study of decades of glaucoma progress a practical component of laboratory research not previously available.

This research was supported by NEI Grant 5 R01 EY04460 to W W Dawson, NIH Grant P40 RR3640 to the Caribbean Primate Research Center, and an unrestricted grant from Research to Prevent Blindness to the Department of Ophthalmology, University of Florida. We thank Ms K Foli and Dr R Ofri for thei efforts in electrophysiological evaluation, and Ms J Clarke for her efforts which produced the manuscript.

1 Rawlins RG, Kessler MJ. The Cayo Santiago macaques. Albany, NY: State University of New York Press, 1986.

2 Dawson $W$, Ulshafer R, Engel H, Hope G, Kessler $M$. Macular disease in related rhesus monkeys. Doc Ophthalmol 1989; 71: 253-64.

3 Dawson W, Engel H, Hope G, Kessler M, Ulshafer R. Ageonset macular degeneration. Puerto Rican Hlth Scif 1989; 8: $111-5$.

4 Engel $\dot{H}$, Dawson W, Ulshafer $R$, Hines $M$, Kessler $M$ Degenerative changes in a community of rhesus monkeys. Ophthalmologica 1988; 196: 143-50.

5 Ulshafer R, Engel H, Dawson W, Allen C, Kessler $M$ Macular degeneration in a community of rhesus monkeys. Retina 1989; 7: 198-203.

6 Hope G, Dawson W, Engel H, Ulshafer R, Kessler M Sherwood $M$. A primate model for age-related macular drusen. Br F Ophthalmol 1992; 76: 11-6.

7 Samuelson D, Dawson W, Brooks D, Dawson J, Hope G Engel $\mathrm{H}$, et al. Monkey optic nerve changes in spontaneous ocular hypertension. Invest Ophthalmol Vis Sci 1991; 32 (suppl): 717

8 Radius R, Anderson D. Reversibility of optic nerve damage in primate eyes subjected to intraocular pressure above systolic blood pressure. Br f Ophthalmol 1981; 65: 661-72.

9 Lee P-Y, Podos S, Howard-Williams J, Severin C, Rose A,
Siegel J. Pharmacological testing in the laser-induced glaucoma model. Curr Eye Res 1985; 4: 775-80.

10 Johnson M, Drum B, Quigley H, Sanchez R, Dunkelberger G. Pattern-evoked potentials and optic nerve fiber loss in monocular laser-induced glaucoma. Invest Ophthalmol Vis Sci 1989; 30: 897-907.

11 Dawson W, Stratton R, Hope G, Parmer R, Engel H, Kessler $M$. Tissue responses of the monkey retina: tuning and dependence on inner layer integrity. Invest Ophthalmol Vis Sci 1986; $27: 734-45$.

12 Trick G. Pattern reversal retinal potentials in ocular hypertensives at high and low risk of developing glaucoma. Doc Ophthalmol 1987; 65: 79-85.

13 Weinstein G, Arden G, Hitchings R, Ryan S, Calthorpe C, Odom V. The pattern electroretinogram (PERG) in ocular hypertension and glaucoma. Arch Ophthalmol 1988; 106: 923-8.

14 Wickham M, Warthen D, Downing D. A randomized technique of constant-pressure infusion. Invest Ophthalmol Vis Sci 1976; 15: 1010-3.

15 Quigley H, Hohman R. Laser energy levels for trabecular meshwork damage in the primate eye. Invest Ophthalmol Vis Sci 1986; 104 (suppl): 1648

16 Sanchez R, Dunkelberger G, Quigley H. The number and diameter of axons in the monkey optic nerve. Invest Ophthalmol Vis Sci 1986; 27 : 1342-50.

17 Quigley H, Sanchez R, Dunkelberger G, L'Hernault N, Baginski T. Chronic glaucoma selectively damages large optic nerve fibers. Invest Ophthalmol Vis Sci 1987; 28: 913-

18 Leydhecker W, Akiyama K, Neumann H. Der intraoculare druck gesunder mensclicher augen. Klin Monatsbl Augenheilkd 1958; 133: 662-70.

19 Shiose Y, Kawase Y. A new approach to stratified normal intraocular pressure in a general population. $A m \mathcal{7}$ Ophthalmol 1986; 101: 714-22.

20 Bito L, Merritt S, De Rousseau C. Intraocular pressure of rhesus monkeys (

21 Ordy J, Brizzee K, Hansche J. Visual acuity and foveal cone density in the retina of the aged rhesus monkey. Neurobiol Aging 1980; 1: 113-40.

22 Hoskins H, Hetherington J, Shaffer R, Welling A. Developmental glaucomas: diagnosis and classification. Proc New Orleans Acad Ophthalmol Glaucoma Symposium. St Louis: Mosby, 1980.

23 Schuman J, Chang W, Wang W, DeKater A, Allingham R, Lin C. Excimer laser effects on outflow facility and outflow pathology morphology. Invest Ophthalmol Vis Sci 1992; 33: 1017.

24 Potts A, Hodges D, Shelman C, Fritz K, Levy N, Mangall Y. Morphology of the primate optic nerve. I. Method and total fiber count. Invest Ophthalmol Vis Sci 1972; 11: 980-8.

25 Newell F. Ophthalmology: principles and concepts. St Louis: Mosby, 1982: 339-43.

26 Chandler P, Grant W. Glaucoma. Philadelphia: Lea \& Febiger, 1979: 3 .

27 Werner E. Low-tension glaucoma. In: Shields M, Krupin T, eds. The glaucomas. Vol 2. St Louis: Mosby, 1989: 797-812. 28 Schwartz B. Primary open-angle glaucoma In: Duane T, Jaeger E, eds. Clinical ophthalmology. Vol 3. New York: Lippincott, 1988: 1-45.

29 Davies T. Topographic survey of close relatives of patients with chronic simple glaucoma. Br $\mathcal{F}$ Ophthalmol 1968; 52: 32.

30 Hovding G, Aasved H. Prognostic factors in the development of manifest open-angle glaucoma. A long-term follow up study of hypertensive and normotensive eyes. Acta Ophthalmol 1986; 64: 601-8.

31 Gelatt K. Familial glaucoma in the beagle dog. 7 Am Anim Hosp Assoc 1972; 8: 23-8.

32 Gelatt K. Veterinary ophthalmology. Philadelphia: Lea \& Febiger, 1991: 66

33 Kalvin N, Hamasaki D, Gass J. Experimental glaucoma in monkeys. I. Relationship between intraocular pressure and cupping of the optic disc and cavernous atrophy of the optic nerve. Arch Ophthalmol 1966; 76: 82-93.

34 Quigley HA, Dunkelberger GR, Green WR. Chronic human glaucoma causing selectively greater loss of large optic nerve fibers. Ophthalmology 1988; 95: 357-63.

35 Fischer R, Rong-Fang W, Podos S, Brodie S. Duration of ocular hypertension in experimentally induced glaucoma. Invest Ophthalmol Vis $S_{c i}$ 1992; 33 (suppl): 1161 .

36 Feghali JG, Jin JC, Odom JV. Effect of short-term intraocular pressure elevation on the rabbit electroretinogram. Invest pressure elevation on the rabbit electr.

37 Songhomitra P, Jonas J, Naumann G. Human photoreceptor count in glaucomatous eyes. Invest Ophthalmol Vis Sci 1991; 32 (suppl): 717

38 Shou TD, Zhou YF. Y cells in the cat retina are more tolerant than X cells to brief elevation of IOP. Invest Ophthalmol Vis Sci 1989; 30: 2093-8.

39 Drance S, Sweeney V, Morgan R, Feldman F. Studies of factors involved in the production of low-tension glaucoma Arch Ophthalmol 1973; 89: 457-65.

40 Leske $M$. The epidemology of open-angle glaucoma: a review. Am F Epidemiol 1983; 118: 166-91.

41 Levene $R$. Low-tension glaucoma: a critical review and new material. Surv Ophthalmol 1980; 24: 621-64.

42 Quaranta L, Manni G, Ripandell G, Bucci M, Langham M. Blood flow in patients with normal tension glaucoma. Invest Ophthalmol Vis Sci 1992; 33 (suppl): 1277

43 Nasemann J, Carl T, Pamer S. Delayed carotid-retinacirculation time in low-tension glaucoma. Invest Ophthalmol Vis Sci 1992; 33 (suppl): 1277. 